\title{
$\nabla$ \\ A Prospective Study of Post-Operative Surgical Site Infection
}

\section{IJCRR}

Section: Healthcare

Sci. Journal Impact

Factor: 6.1 (2018)

ICV: 90.90 (2018)

(c) (i) (5)

Copyright@IJCRR

\section{Ketul Shah ${ }^{1}$, Rohit Singh ${ }^{2}$, Pratik Shapariya ${ }^{1}$, Honeypalsinh H Maharaul ${ }^{3}$}

'Assistant Professor, Department of Surgery, Smt. B.K. Shah Medical Institute \& Research Centre Sumandeep Vidyapeeth \& Institution Deemed To Be University, Pipariya, Vadodara, India; ${ }^{2}$ Resident, Department of Surgery, Smt. B.K. Shah Medical Institute \& Research Centre Sumandeep Vidyapeeth \& Institution Deemed To Be University, Pipariya, Vadodara, India; ${ }^{3}$ Associate Professor, Department of Surgery, Smt. B.K. Shah Medical Institute \& Research Centre Sumandeep Vidyapeeth \& Institution Deemed To Be University, Pipariya, Vadodara, India.

\section{ABSTRACT}

Introduction: Procedures causing a break in the skin continuity, the natural barrier against infection, predisposes to infection. SSIs are defined as a discharge that may be serous or purulent discharge and presents within 30 days of a surgical procedure (within 1 year in case of a prosthetic implant). There is an emerging problem of SSls due to resistant organisms.

Objective: To identify the possible risk factors related to the development of SSIs and the common pathogens encountered in the development of SSIs.

Methods: This is prospective, observational study. Patients of either gender that aged more than or equal to 18 years, who reported to the surgery department and underwent either elective or emergency surgeries and developed post-operative surgical site infections were included after taking consent. A swab was collected and sent to the microbiology department for culture and sensitivity reports.

Results: A total of 103 patients with surgical site infection were enrolled. SSIs were predominant in males (62.14\%) as compared to females (37.86\%). The mean age of the patients was $52.58 \pm 19.77$ years. Maximum patients were in the age group of 58 to 77 years. SSIs were common in surgeries performed in an emergency setting rather than those performed electively. SSIs were common in a contaminated wound (45.63\%) followed by dirty wounds $(28.16 \%)$. History of hospitalization is positively correlated with the development of SSIs.

Conclusion: Both, patients, as well as a surgical factor, acts as the risk for its development. Each hospital must have its list of antimicrobials to be used for empirical therapy. An antimicrobial stewardship program needs to be implemented to bring this incidence of resistant SSIs down.

Key Words: Surgical Site Infection, Wound, Antibiotics, Skin, Pathogens

\section{INTRODUCTION}

Procedures causing a break in the skin continuity, the natural barrier against infection, predisposes to infection. ${ }^{1}$ It also means that surgery, a planned breach in the skin continuity, also exposes patients to a risk of postoperative infection. These have created problems since the inception of surgery and are considered a surgeon's nightmare. The infection impairs wound healing and cause significant morbidity and sometimes mortality. ${ }^{2}$ These infections are categorized under the broad term of nosocomial infections. They are the $2^{\text {nd }}$ most common cause of nosocomial infections just after urinary tract infection. It leads to prolongation in the hospital stay, which not only imposes a cost burden but also causes significant morbidity and mortality.
Grossly any purulent discharge that comes out of a closed surgical incision and is associated with signs of inflammation in the surrounding tissue should be regarded as wound infection, whether the micro-organisms can be cultured from it or not. The definition of surgical site infection was first of all provided by Horan and colleagues. This greatly helped in differentiating it from the term which was used earlier as wound infection These infections at different surgical sites were then classified into majorly 3 groups. The basis of this classification was the site and extent of infection., These 3 groups were namely, 1. Superficial incisional SSIs, 2. Deep incisional SSIs and 3. Organ-space SSIs. ${ }^{3}$ These CDC has accepted this definition. It is also used widely across the United States of America and European nations. ${ }^{3}$

\section{Corresponding Author:}

Dr. Honeypalsinh H Maharaul, Associate Professor, Department of Surgery, Smt. B. K. Shah Medical Institute \& Research Centre Sumandeep Vidyapeeth \& Institution Deemed To Be University, Pipariya, Vadodara, India; PH: 9426345105; Email: honeypal.219@gmail.com

ISSN: 2231-2196 (Print)

Received: 12.08 .2020

$$
\text { ISSN: 0975-5241 (Online) }
$$

Revised: 22.09 .2020
Accepted: 24.11 .2020
Published: 05.01 .2021 
Discharge that may be serous or purulent discharge and presents within 30 days of a surgical procedure (within 1 year in case of a prosthetic implant). Superficial incisional SSI's are limited to the skin and subcutaneous tissue at the site of incision It has at least one of the below-mentioned feature:

1. There is purulent drainage from the incision The purulent drainage may or may not have been confirmed in labs.

2. The culture of fluid/tissue which is obtained from the site of incision shows other growth of the organisms.

3. There is the presence of at least one of the signs or symptoms of infection. These infections may be associated with certain symptoms like pain or tenderness, local swelling, There may also be redness or heat. These superficial incisions are also intentionally left open by the surgeon.

4. A Surgeon or attending physician making a diagnosis of superficial incisional.

Deep incisional SSIs are kinds of infections, there is the involvement of deep tissues like fascial and muscle layers.

1. Organ space SSI's- Herein the infection involves distant sites such as the organs or spaces which are not opened or manipulated during operation.

These infections are highly prevalent in low to middle-income countries, but this does not mean that developed nations are free from SSIs. Globally around 2 million cases of SSIs occur annually. ${ }^{4} \mathrm{WHO}$ describes these as one of the major infectious diseases having a significant economic impact. ${ }^{5}$ The prevalence of SSIs varies widely from region to region to region and hospital to hospital to hospital, grossly it ranges between 5-16\%. In India, per se literature reveals that the prevalence of SSI varies between $5 \%$ and $24 \%$.

Various factors affect the susceptibility of any wound to the infection, these may be related to a patient, type of surgery, type of wound, surgical technique, surgeons experience, etc. The factors related to patients that influence the development of SSIs are as following: extremes of age, patient's immunity, comorbidities such as diabetes mellitus, malnourishment both obesity as well as undernourished and presence of anaemia, patient's lifestyle including alcohol and drug abuse, smoking and lack of exercise or sleep. ${ }^{6}$

These factors start right from the duration of the preoperative stay of the patient in the hospital. Common factors that act as risks for SSIs are shaving technique of the operative site, surgical procedure type, surgeon skills, duration of surgery, prophylactic use of antibiotics, and pre-operative use of drugs such as steroid therapy that have the potential to cause immune-suppression. With the increased use of diagnostic and treatment modalities, there is increased bacterial exposure of the patient. ${ }^{6}$
These factors are the bacterial inoculum that gets introduced into the wound either during the procedure or immediately after the procedure, the degree of virulent nature of the micro-organisms. Toxins produced by microorganisms increase their ability to invade host tissue and produce damage to the host tissue. Gram-negative bacteria are known to produce endotoxin that stimulates cytokine production. These cytokines, in turn, can trigger the systemic inflammatory response syndrome which causes significant morbidities and may even cause multiple system organ failures. ${ }^{7-9}$

The presence of necrosis, hematoma, or dead space provides a milieu for the growth of bacteria. The presence of foreign bodies inhibits local tissue resistance and allowing uninhibited bacterial growth. ${ }^{8}$ The wound microenvironment influences bacterial growth. With this, it can be seen that the incidence of infection is affected by factors that are intrinsic to the patient and factors related to the type and circumstances of surgery. Thus, as a result of exogenous or endogenous bacterial contamination of the operative procedure SSIs develop. Host - bacteria equilibrium gets disturbed and the equilibrium is one that is in the favour of bacteria. The common causative agents are gram-positive cocci and gramnegative bacilli. However, a variety of aerobic and anaerobic species of bacteria may co-exist.

The presence of these bacteria induces an inflammatory reaction that causes tissue destruction and ultimately pus formation. Bacteria involved in pus formation are labelled as "pyogenic" (pus producing). CDC Study on the Efficacy of Nosocomial Infection Control (SENIC) suggested the following four risk factors for the development of SSIs: ${ }^{7}$

1. Operation involving abdomen;

2. Operation lasting beyond 2 hours;

3. Operations that are classified as contaminated, dirty, or infected; and

4. Patient having multiple diagnoses at discharge.

With the advancement in the field of medicine, there is a possibility of prevention and control of these infections. With the discovery of anti-microbial agents even dirty surgeries can be performed without the risk of mortality. In 1964, the US National Research Council group had classified the operative wounds. This classification was done based on the degree of microbial contamination, It then proposed 4 wound classes. Each class had an increased risk of SSIs. These 4 classes were namely:

1. Clean

2. Clean and contaminated

3. Contaminated

4. Dirty $^{10}$

With the progress of time and wide use and misuse of antimicrobial agents, anti-microbial, once referred to as "MAGIC BULLETS" to eradicate the infection, have seemed to fail in 
their purpose. The use of antimicrobial agents for the prevention of surgical site infection has become controversial and a disappointment in surgical practice, as the widespread use of antimicrobials has resulted in the problem of the emergence of resistance among micro-organisms. This had made it difficult to control, eliminate, or completely eradicate the surgical site infection. ${ }^{11}$

The advances that have been made to reduce the incidence of SSI are improvement in the operating theatre ventilation, proper sterilization methods, use of barriers, improved surgical technique, etc, but the rate of SSIs has not zeroed. On the other hand, there is an emerging problem of SSIs due to resistant organisms. ${ }^{4}$ It is a must to combine advances in the field of microbiology with the advances in the field of surgery. It is a must to understand the bacteriology and emergence of resistance patterns of bacteria properly and use the antibiotics judiciously and meticulously to deal with this menace of SSIs due to resistant organisms. Thus it is pertinent that every hospital has an overall understanding of all the aspects of surgical site infections. The present study was undertaken to identify the possible risk factors related to the development of SSIs and the common pathogens encountered in the development of SSIs. Identifying the pathogens and their antimicrobial sensitivity will ultimately help in the empirical management of SSIs.

\section{MATERIALS AND METHODS}

We conducted this prospective, observational study in the Surgical Department of Dhiraj General Hospital, Piparia. This study was conducted throughout one and a half years that is from January of 2018 to June of 2019. The patients that met all the criteria for inclusion and none of the criteria for exclusion were enrolled in the study. The study was conducted as per Institutional ethical approval no: SVIEC/ON/ MEDI/BNPG17/D18034 guidelines as well as the bioethical guidelines provided by ICMR 2016 and in accordance to ICH (International Conference on Harmonization) E6 (R2) 'Guideline for Good Clinical Practice'.

\section{Inclusion criteria}

- $\quad$ Patients of either gender aged more than or equal to 18 years.

- All patients who reported to the surgery department and underwent either elective or emergency surgeries.

- Patients who developed postoperative surgical site infections.

- The patient gave written informed consent.

\section{Exclusion criteria}

1. Patients having a history of previous surgical site infection.

2. Patients who received antibiotics more than a week before surgery.
3. Patients that underwent re-operation, except for the management of surgical site infection.

4. Patients who took DAMA, or did not follow up within 30 days of operation.

5. The patient did not want to participate in the study.

A swab was collected and sent to the microbiology department for culture and sensitivity reports. The patient was also investigated for: complete blood count, urine routine and microscopy, random blood sugar, liver function test, renal function test, ECG, chest x-ray PA view, and other special investigations like CT scan, if required.

The findings were computed and analyzed.

\section{RESULTS AND DISCUSSION}

\section{Gender comparison}

In the present study, we observed that SSI was predominant in males as compared to females, of the 103 patients were enrolled with surgical site infection $62.14 \%$ were males while $37.86 \%$ were females (Table 1). Similar findings were also observed by Chada et al., 2017 in their study the authors observed that males with SSI were $61 \%$ while $39 \%$ of females had SSIs. ${ }^{6}$ Saxena et al., 2013 also observed that the SSIs were common in males as compared to females. ${ }^{2}$ In contrast to our study, Khairy et al., 2011 observed that SSIs were common in females rather than males. ${ }^{12}$ Bandaru et al., 2012 and Kikkeri et al., 2014 also observed that SSI was common in males. ${ }^{10,13}$ One of the reasons for these gender differences could be the biological differences between the skin of men and women. Studies have shown that there is greater colonization with bacteria of the skin surrounding the insertion site of a central venous catheter in men than in women, even when controlling for baseline colonization. ${ }^{14}$ Additionally adherence to wound dressing is impacted by hair growth and shaving, and this may be responsible for the higher risk of infection among men that have thicker, coarser hair.

\begin{tabular}{|c|c|c|c|c|c|}
\hline & $\begin{array}{l}\text { Present } \\
\text { study }\end{array}$ & $\begin{array}{c}\text { Chada } \\
\text { CKR et } \\
\text { al., } 2017^{6}\end{array}$ & $\begin{array}{c}\text { Saxena } \\
\text { A et al., } \\
2013^{2}\end{array}$ & $\begin{array}{l}\text { Bandaru } \\
\text { NR et } \\
\text { al., 2012 }\end{array}$ & $\begin{array}{c}\text { Kikkeri } \\
\text { N et al. } \\
2014^{13}\end{array}$ \\
\hline Male & $62.14 \%$ & $61 \%$ & $79.07 \%$ & $64.29 \%$ & $82.1 \%$ \\
\hline Female & $37.86 \%$ & $39 \%$ & $20.93 \%$ & $35.71 \%$ & $17.9 \%$ \\
\hline
\end{tabular}

\section{Age distribution}

In the present study, the mean age of the patients was 52.58 \pm 19.77 years and maximum patients were in the age group of 58 to 77 years (Table 2). In the study by Mahesh CB et al., 2010, the incidence of SSIs increased with advanced age, the authors observed that $33.33 \%$ of patients in the age group of 
$61-70$ yrs and $46.66 \%$ of patients in the age group of $>70$ yrs were infected..$^{15}$ In contrast to this Khairy et al., 2011 observed that SSIs were common in the age group $>12$-19years. ${ }^{16}$ In the study by Kikkeri et al.,2014, the majority of the patients with SSIs were in the age group of $18-30$ years, $64.44 \% .^{13}$
Saxena et al., 2013 observed that age $>50$ years is a risk factor for the post-operative wound infections. ${ }^{2}$ This may be because of the co-morbidities, impaired immunity with advancing age, low healing rate, malnutrition, mal-absorption, and increased catabolic processes.

Table 2: Comparison of the age distribution of the present study with that of literature.

\begin{tabular}{|c|c|c|c|c|c|c|c|c|}
\hline & $\begin{array}{l}\text { Present } \\
\text { study }\end{array}$ & $\begin{array}{l}\text { Mahesh et } \\
\text { al., } 2010^{1} 5\end{array}$ & $\begin{array}{c}\text { Chada et al., } \\
2017^{6}\end{array}$ & $\begin{array}{c}\text { Cheng et al., } \\
2015^{17}\end{array}$ & $\begin{array}{l}\text { Saxena et } \\
\text { al., } 2013^{2}\end{array}$ & $\begin{array}{c}\text { Bandaru et } \\
\text { al. }^{10}\end{array}$ & $\begin{array}{l}\text { Kikkeri et } \\
\text { al., 2014 }\end{array}$ & 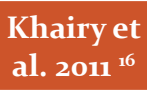 \\
\hline $\begin{array}{l}\text { Mean age } \\
\text { (years) }\end{array}$ & $\begin{array}{c}52.58 \pm \\
19.77\end{array}$ & 32.2 & $\begin{array}{c}34 \cdot 5 \pm 14.2 \\
\text { years }\end{array}$ & 54.62 & & & & \\
\hline $\begin{array}{l}\text { Pre dominant } \\
\text { age group } \\
\text { (years) }\end{array}$ & $58-77$ & $>51$ & $18-26$ & $>75$ & $>50$ & $>60$ & $>50$ & $12-19$ \\
\hline
\end{tabular}

\section{Comparison of SSI in Emergency vs elective surgery}

In the present study, we observed that SSIs were common in surgeries performed in an emergency setting rather than those performed electively. Of the patients with SSIs, $56.31 \%$ had undergone surgeries under emergency settings while another $43.69 \%$ had undergone surgeries in an elective setting (Table 3). In the study by Chada et al.,2017, of the patients with SSIs, $56 \%$ had undergone surgeries under emergency settings while another $44 \%$ had undergone surgeries in an elective setting. ${ }^{6}$ Saxena et al., 2013 the infection rate was $16.48 \%$ in patients operated in an emergency setting while in patients operated electively the rate was $13.39 \% .{ }^{2}$ Similar findings were also observed by Khairy et al. 2011 14.28\% of the patients operated in emergency setting developed SSIs while only $3.37 \%$ operated in the elective setting developed SSIs (Table 3). ${ }^{16}$ Since the surgeries performed under emergency lack routine pre-op preparations such as management of co-morbidity, control of diabetes, etc. Also, the fact that emergency operations involve contaminated areas like bowel and the perianal region.

Table 3: Comparison of emergency/elective surgery with that of literature.

\begin{tabular}{lccccc} 
& $\begin{array}{c}\text { Present } \\
\text { study }\end{array}$ & $\begin{array}{c}\text { Chada } \\
\text { CKR et } \\
\text { al., 2017 }\end{array}$ & $\begin{array}{c}\text { Cheng } \\
\text { K et al., } \\
2015^{17}\end{array}$ & $\begin{array}{c}\text { Saxena } \\
\text { A et al., } \\
2013^{2}\end{array}$ & $\begin{array}{c}\text { Khairy } \\
\text { GA et al., } \\
\mathbf{2 0 1 1}^{16}\end{array}$ \\
Emergency & $56.31 \%$ & $56 \%$ & $8.4 \%$ & $16.48 \%$ & $14.28 \%$ \\
Elective & $43.69 \%$ & $44 \%$ & $2.5 \%$ & $13.39 \%$ & $3.37 \%$ \\
\hline
\end{tabular}

*- These studies have reported the incidence of SSIs.

\section{Comparison of SSI in different wounds}

We observed that the rate of SSIs was common in a contaminated wound $(45.63 \%)$ followed by dirty wounds $(28.16 \%)$ (Table 4). We observed a lower incidence in operations labeled as dirty as compared to contaminated wounds is because we choose patients who had already developed SSIs and the overall incidence of operations labeled as dirty in that group was lower as compared to operations labeled as contaminated. This classification of operations is based on the probability of developing the SSIs following operations. The probability of contamination and thereby the chances of developing SSIs increases as the type of operation proceeds from clean to dirty. However, with proper aseptic precautions and proper use of antibiotics, the risk of SSIs can be reduced.

Table 4: Comparison of SSIs based on the type of operation with different literature.

$\begin{array}{lccccc}\begin{array}{l}\text { Type of } \\ \text { operation }\end{array} & \begin{array}{c}\text { Present } \\ \text { study }\end{array} & \begin{array}{c}\text { Chada } \\ \text { CKR et } \\ \text { al.,2017 }\end{array} & \begin{array}{c}\text { Saxena } \\ \text { A et al., } \\ 2^{2013^{2}}\end{array} & \begin{array}{c}\text { Khairy } \\ \text { GA et } \\ \text { al.2011 }\end{array} & \begin{array}{c}\text { Kikkeri } \\ \text { N et }\end{array} \\ \begin{array}{l}\text { al.,2014 } \\ \text { Clean }\end{array} & 9.71 \% & 10 \% & 12.1 \% & 4.6 \% & 5.94 \% \\ \begin{array}{l}\text { Clean con- } \\ \text { taminated }\end{array} & 16.50 \% & 19 \% & 15.2 \% & 6.2 \% & 9.28 \% \\ \begin{array}{l}\text { Contami- } \\ \text { nated }\end{array} & 45.63 \% & 35 \% & 13.04 \% & 12.5 \% & 55.56 \% \\ \begin{array}{l}\text { Dirty } \\ 28.16 \%\end{array} & 32 \% & 60 \% & - & 22.22 \%\end{array}$

\section{Correlation of SSI with hospitalization}

When the history of hospitalization in the past 6 months was evaluated, it was observed that $73.79 \%$ of patients had undergone hospitalization in the past 6 months due to some or other reasons. History of hospitalization is positively correlated with the development of SSIs. Similar to our study Chada et al.,2017 observed that prior hospitalization had taken place in $74 \%$ of the study population (Table 5 ). ${ }^{6}$ Saxena et al., 2013 evaluated the impact of pre-operative stay on SSIs in elective surgeries and observed that there was a positive correlation between pre-operative stay and SSIs in case of elective surgeries. Various literature also suggests that there is a positive correlation between the pre-operative waiting period and the development of SSIs, Kikkeri et al., 2014 observed that SSIs developed in $9 \%$ of patients operated in less 
than 48 hours and in $43 \%$ of patients who waited for more than a week to undergo surgery. ${ }^{13}$ Mahesh CB et al.,2010 also observed a direct correlation between pre-operative hospitalization and the development of SSIs. ${ }^{15}$ The reason for the higher incidence of infections with prolonged hospitalization could be the colonization of patients with nosocomial strains in the hospital. Also, longer pre-operative stay in the hospital reflects the severity of existing illness and the presence of co-morbid conditions that may have required workup and management before the operation.

Table 5: Prior hospitalization with that of literature.

\begin{tabular}{lc} 
Literature & Prior hospitalization (\%) \\
Present study & $73.79 \%$ \\
Chada CKR et al., 2017 & $74 \%$ \\
\hline
\end{tabular}

\section{Correlation of SSI with diabetes mellitus}

Diabetics are at higher risk of infections; uncontrolled diabetics are at even higher risks. This is because of impaired micro-circulation and sugar-rich blood providing ideal media for bacterial growth. In the present study, we observed that SSIs occurred in $37.86 \%$ of patients with uncontrolled diabetics, $28.16 \%$ with controlled diabetics, and $33.98 \%$ without diabetics (Table 6). Thus, in the present study of the developing SSIS, $66.02 \%$ had diabetes, either controlled or uncontrolled. In the study by Chada et al., $2017,39 \%$ of patients had uncontrolled diabetes while $27 \%$ of patients had controlled diabetes. ${ }^{6}$ Saxena et al., 2013 observed that the incidence of SSIs was $24.13 \%$ in diabetics while the same was $13.28 \%$ in non-diabetics. ${ }^{2}$ Kikkeri et al.,2014 observed that $83.33 \%$ of diabetes developed SSIs while it was observed in only $12.18 \%$ of patients without diabetes. ${ }^{13}$ Khairy et al., 2011 observed that the incidence of SSIs was $20 \%$ and $3.77 \%$ in diabetics and non-diabetics respectively. ${ }^{16} \mathrm{Cheng}$ et al., 2015 observed that the incidence of SSIs in diabetics and nondiabetics was $14.3 \%$ and $2.5 \%$ respectively. ${ }^{17}$ Apart from diabetes various other co-morbidities impact the outcome in patients, these factors are BMI (both the extremes that are malnourishment as well as obesity), anaemia, etc.

Table 6: Diabetes history.

\begin{tabular}{lc} 
Literature & The proportion of diabetics (\%) \\
Present study & $66.02 \%$ \\
Chada CKR et al., 2017 & $66 \%$ \\
Kikkeri N et al., 2014 & 13 \\
Khairy GA et al., 2011 & $63.33 \%$ \\
\hline
\end{tabular}

\section{Comparission of operative procedure and SSI}

In the present study of the patients that developed SSIs, laparotomy, cholecystectomy, appendicectomy and amputations were performed in $35.92 \%, 23.30 \%, 21.36 \%$, and $19.42 \%$ of the patients respectively (Table 7). Most of these operations are classified as clean-contaminated or dirty. In the study by Chada et al., 2017, of the patients with SSIs, 4.9\% had undergone amputation, $7.1 \%$ had undergone appendicectomy and $17.6 \%$ patients had undergone laparotomy. ${ }^{6}$ In the study by Olowo-okere et al., $2018>30 \%$ of patients that underwent exploratory laparotomy and appendicectomy developed SSIs. ${ }^{18}$ Laparotomy is a contaminated type of operation and hence at a high risk of developing SSIs, which was also observed in the present study.

Table 7: Operative procedure performed in the present study as compared to literature

\begin{tabular}{lccc} 
Type of surgery & $\begin{array}{c}\text { Present } \\
\text { study }\end{array}$ & $\begin{array}{c}\text { Chada et al., } \\
2017,{ }^{6}\end{array}$ & $\begin{array}{c}\text { Olowo-okere } \\
\text { et al., 2018 }\end{array}$ \\
\hline Laparotomy & $35.92 \%$ & $17.6 \%$ & \\
Cholecystectomy & $23.30 \%$ & - & $>30 \%$ \\
Appendicectomy & $21.36 \%$ & $7.1 \%$ & \\
Amputations & $19.42 \%$ & $4.9 \%$ & \\
\hline
\end{tabular}

\section{Comparison of bacterial growth}

In the present study of the 100 swabs collected, gram stain showed pus cells in $96.12 \%$ while bacteria were seen in $94.17 \%$ (Table 8). Bacterial growth in culture was obtained in 94 swabs $(91.26 \%)$. In the study by Chada CKR et al., 2017 , pus cells were seen in $92 \%$ of cases undergoing gram staining, and bacteria were seen in $94 \%$ of cases. Bacterial growth was obtained in $91 \%$ of culture cases. Bandaru et al., 2012 reported growth was seen in culture in $83 \%$ (35 out of 42) of cases. Arora et al., 1990, and colleagues (87\% cases) and Masood Ahmed et al., 2007 also reported positive cultures for their SSI cases. ${ }^{19,20}$

\begin{tabular}{|c|c|}
\hline Literature & $\begin{array}{l}\text { The proportion of swabs with } \\
\text { bacterial growth on culture (\%) }\end{array}$ \\
\hline Present study & $91.26 \%$ \\
\hline Chada CKR et al.,2017 ${ }^{6}$ & $91 \%$ \\
\hline Bandaru NR et al.,2012 ${ }^{10}$ & $83 \%$ \\
\hline Arora et al.,1990 ${ }^{20}$ & $87 \%$ \\
\hline
\end{tabular}

In the present study, staphylococcus aureus (23.30\%) was the commonest bacterial isolate (Table 9). Similar findings were also observed by Kownhar et al., 2008 the authors reported that of all the isolates, $37 \%$ were staphylococcus aureus of which MRSA was $27 \%{ }^{21}$ Chada et al., 2017 reported Staphylococcus aureus in $25.34 \%$ of the cases. ${ }^{6}$ The common isolates various from study to study and depend on the hospital, its location, common nosocomial organism prevalent, other physical and operational factors, etc. A literature review has shown that some authors have reported major iso- 
lates of Pseudomonas aeruginosa and Escherichia coli also in their studies. Bandaru et al., 2012 reported staphylococcus aureus ( $38 \%$ cases) followed by Escherichia coli as the common pathogens causing post-operative wound infections. ${ }^{10}$

Table 9: Common isolate on culture in different studies.

\begin{tabular}{ll} 
Literature & $\begin{array}{l}\text { The proportion of swabs with bacterial } \\
\text { growth on culture (\%) }\end{array}$ \\
$\begin{array}{l}\text { Present study } \\
\text { Kownhar H et } \\
\text { al., } 2008^{21}\end{array}$ & $\begin{array}{l}\text { Staphylococcus aureus (23.30\%) } \\
\text { Chada CKR et } \\
\text { al., } 2017^{6}\end{array}$ \\
$\begin{array}{l}\text { Bandaru NR et } \\
\text { al., 2012 }{ }^{10}\end{array}$ & Staphylococcus aureus (25.34\%) \\
\hline
\end{tabular}

Staphylococcus aureus was a major isolate across all the different type of surgeries. Chada CKR et al., 2017observed that staphylococcus aureus was a major isolate from orthopedic SSI, followed by L.S.C.S. surgeries and was common in an emergency procedure. In the study by Chada et al., 2017, MRSA was seen in $37 \%$ of S aureus isolates ${ }^{6}$ Contradictory to our study, Chada et al., 2017, Bericon et al., 2007 and Anvikar et al.,1999 reported higher isolation of E.coli and Klebsiella pneumoniae from surgical wards. ${ }^{6,22,28}$ In the present study, of the various gram-negative organisms isolated, Escherichia coli and Pseudomonas aeruginosa were predominant. Suljagic et al., 2010 reported that E.coli was the major isolate from intestinal and abdominal surgeries. ${ }^{24}$ Staphylococcus aureus are common contaminants in various parts of the hospitals. Bedsheets, instruments, and dressing material are known to act as reservoirs for infections. Mehta et al., 2014 collected 196 swabs/pus specimens from different parts of a surgical unit, they found that Staphylococcus aureus was predominant as contaminant, which explains the predominance of Staphylococcus aureus as a causative organism for SSIs. ${ }^{29}$

We observed that isolated Staphylococcus aureus was resistant to various antibiotics such as amoxicillin, ampicillin, etc. which was also the observation in other studies. ${ }^{25,26} \mathrm{We}$ also observed that a higher proportion of Staphylococcus aureus strains was also resistant to Amoxycillin + clavulanic acid and this has resulted in a decline in the use of this antibiotic for the treatment of SSIs with S aureus. We also observed that MRSA infection is widespread, which is also confirmed by other studies. Some strains of Staphylococcus aureus were also resistant to clindamycin. Despite resistance to various antibiotics, no resistance was not observed to vancomycin and linezolid in the present study.

CONS that were isolated in the present study showed a high degree of resistance to various antibiotics. However, none were resistant to vancomycin and linezolid. Chada et al., 2017and Cantlon et al., 2006 also reported CONS isolates that were resistant to various organisms. ${ }^{6,27}$ Rudresh et al., $2012^{30}$ concluded adequate antibiotic prophylaxis is just not sufficient for the prevention of salmonella infection of the port in chronically infected gall bladder extraction. Every gallbladder should be extracted with an endo bag especially in developed countries, where the chances of chronic Salmonella infections are common.

In the present study, gram-negative isolates showed a high degree of resistance to commonly used low generation antibiotics. These were the observation in the various other studies also. One of the reasons for the emergence of resistance is the widespread empirical use of antibiotics for various infections. Most gram-negative isolates demonstrated multidrugresistant. However, these organisms showed sensitivity to carbapenems like meropenem, imipenem, and doripenem and Piperacillin/tazobactam. Sensitivity to a higher generation of cephalosporins was also preserved by most Pseudomonas aeruginosa and $100 \%$ Proteus $s p$ isolated. With this, it can be recommended that higher generation cephalosporins and carbapenems can be used for empirical management of SSI. Each hospital should develop its list of essential and empirical antibiotic lists and these lists should be updated periodically based on the common nosocomial infections and their resistance pattern.

\section{CONCLUSION}

It can be concluded that SSIs are quite prevalent and there is an emerging menace of multi-drug resistant organisms. Both, patients, as well as a surgical factor, acts as the risk for its development. Each hospital must have its list of antimicrobials to be used for empirical therapy, conduct regular surveillance. Empirical Use of higher antibiotics should be limited to high-risk patients.

\section{ACKNOWLEDGEMENT}

Immeasurable appreciation and deepest gratitude for the help and support are extended to my mentor Dr. Rajesh P Bharaney who in a way or other has contributed to making this study possible.

Conflict of interest: Nil

Source of funding: Nil

\section{REFERENCES}

1. Golia S. A study of superficial surgical site infections in a tertiary care hospital at Bangalore. Int J Res Med Sci 2014 May;2(2):647-652. 
2. Saxena A. Surgical site Infection among postoperative patients of the tertiary care centre in Central India - A prospective study. Asian J Biomed Pharm Sci 2013:3(17);41-44.

3. Horan TC, Gaynes RP, Martone WJ, Jarvis WR, Emori TG. CDC definitions of nosocomial surgical site infections, 1992: a modification of CDC definitions of surgical wound infections. Am J Infect Control 1992;20:271-74.

4. Anusha S, Vijaya LD, Pallavi K, Manna PK, Mohanta GP, Manavalan R. An Epidemiological Study of Surgical Wound Infections in a Surgical unit of Tertiary care Teaching Hospital. Indian J Pharm Pract 2010; 3(4):8-13.

5. Mohamed Issa Ahmed. Prevalence of Nosocomial wound Infection among Postoperative patients and Antibiotics patterns at Teaching Hospital in Sudan. North Am J Med Sci 2012; 4(1);2934.

6. Chada CKR. A prospective study of surgical site infections in a tertiary care hospital. Int Surg J 2017 Jun;4(6):1945-1952.

7. Haley RW, Culver DH, Morgan WM, White JW, Emori TG, Hooton TM. Identifying patients at high risk of surgical wound infection. A simple multivariate index of patient susceptibility and wound contamination. Am J Epidemiol 1985;121(2):20615.

8. Lawal OO, Adejuyigbe O, Oluwole SF. The predictive value of bacterial contamination at operation in postoperative wound sepsis. Afr J Med Sci 1990;19(3):173-9.

9. Demling R, LaLonde C, Saldinger P, Knox J. Multiple-organ dysfunction in the surgical patient: pathophysiology, prevention, and treatment. Curr Probl Surg 1993;30(4):345-414.

10. Bandaru NR. A Prospective Study of Postoperative Wound Infections in a Teaching Hospital of Rural Setup. J Clin Diagn Res 2012;6(7):1266-71.

11. Leuva HL. Role of Antibiotics in Clean Surgeries: Prophylaxis V/S. Conventional. Guj Med J 2014:69(2):96-98.

12. Khairy GA. Surgical Site Infection in a Teaching Hospital: A Prospective Study. J Taibah Uni Med Sci 2011; 6(2): 114-120.

13. Kikkeri N. A study on Surgical Site Infections (SSI) and associated factors in a government tertiary care teaching hospital in Mysore, Karnataka. Int J Med Public Health 2014;4:171-5.

14. Cohen B. Gender Differences in Risk of Bloodstream and Surgical Site Infections. J Gen Intern Med 2013; 28(10):1318-1325.

15. Mahesh CB, Shivakumar S. A prospective study of surgical site infections in a teaching hospital. J Clin Diagn Res 2010;4:31149.

16. Khairy GA. Surgical Site Infection in a Teaching Hospital: A Prospective Study. J Taibah Uni Med Sci 2011; 6(2): 114-120.

17. Cheng K. Risk factors for surgical site infection in a teaching hospital: a prospective study of 1,138 patients. Patient Pref Adher 2015:9;1171-7.
18. Olowo-okere A. Occurrence of Surgical Site Infections at a Tertiary Healthcare Facility in Abuja, Nigeria: A Prospective Observational Study. Med Sci J 2018;6:60.

19. Ahmed M, Alam SN, Khan O, Manzar S. Post-operative wound infections: a surgeon's dilemma: Pakistan J Surg 2007; 23(I):4147.

20. Arora S, Prabhakar H, Garg BB, Jindal N. The anaerobic bacterial flora of wound sepsis. J Indian Med Assoc 1990 Jun;88:1546.

21. Kownhar H, Shankar EM, Vignesh R, Sekar R, Velu V, Rao UA. The high isolation rate of staphylococcus aureus from surgical site infections in an Indian Hospital. J Antimicrob Chemotherap 2008;3:758-60.

22. Kamat U, Ferreira A, Savio R, Motghare D. Antimicrobial resistance among Nosocomial isolates in a teaching hospital in Goa. Indian J Community Med 2008;33:89-92.

23. Bercion R, Gaudeuille A, Mapouka PA, Behounde T, Guetahoun Y. Surgical site infection survey in the orthopaedic surgery department of the "Hospital communautaire de Bangui, Central African Republic. Bull Soc Pathol Exot 2007;100:197-200.

24. Suljagic V, Jevtic M, Djordjevic B, Jovelic A. Surgical site infections in a tertiary health care centre: a prospective cohort study. Surg Today 2010;40:763-41.

25. Andhoga J, Macharia AG, Maikuma IR, Wanyonyi ZS, Ayumba BR, Kakai R. Aerobic pathogenic bacteria in post-operative wounds at Moi Teaching and Referral Hospital. East Afr Med J 2002;79:640-4.

26. Anguzu JR, Olila D. Drug sensitivity patterns of bacterial isolates from septic post- operative wounds in a regional referral hospital in Uganda. Afr Health Sci 2007;7:148-54.

27. Cantlon CA, Stemper ME. Schwan WR, Hoffman MA, Qutaishat SS. Significant pathogens isolated from surgical site infections at a community hospital in the Midwest. Am J Infect Control 2006;34526-9.

28. Anvikar AR, Deshmukh A, Karyakarte RP, Damle AS, Patwardhan NS, Malik AK, et al. One-year prospective study of 3280. Surg Wounds 1999;17:129-32.

29. Mehta S. Nosocomial wound infection amongst post-operative patients and their antibiograms at tertiary care hospital in India. AJCEM 2014:15(2);60-68.

30. Rudresh H. K, Banashankari. G. S, Harsha. A. Huliyappa, Arvind Nayak, Prasannakmar Kabmle. Laparascopic Port Site Infection with Salmonella - Review of Literature. IJCRR 2012;4(14); 6068. 